\title{
O “NOVO" ENSINO MÉDIO: implicações ao processo de legitimação da Educação Física
}

\author{
José Ângelo Gariglio' \\ Admir Soares Almeida Junior² \\ Cláudio Márcio Oliveira ${ }^{3}$
}

\section{RESUMO}

O presente trabalho apresenta reflexões acerca da questão mobilizadora desse periódico, qual seja: "como é possível encontrar ou construir fundamentos para justificar a Educação Física no currículo escolar [do ensino médio] hoje". Para tanto, apresentamos uma discussão sobre os principais aspectos do "Novo" Ensino Médio, dando ênfase às concepções de conhecimento, de currículo, de juventudes e à ruptura da articulação entre as dimensões de formação humana (Ciência, Cultura, Trabalho e Tecnologia) previstos na legislação anterior. Em seguida, retomamos o debate acerca da legitimidade da Educação Física na escola, tomando como referência, entre outras produções, as Orientações Curriculares Nacionais do Ensino Médio escritas em 2006. Por fim, pretendemos apresentar estratégias de enfrentamento do atual contexto, bem como refletir sobre a possibilidade de construirmos outras formas de legitimação da presença e permanência da Educação Física no Ensino Médio.

Palavras-chave: Ensino Médio. Educação Física. Currículo. Política Educacional. Legitimidade Pedagógica.

1 Doutor em Educação. Professor da Escola de Educação Física, Fisioterapia e Terapia Ocupacional da Universidade Federal de Minas Gerais (EEFFTO/UFMG). Belo Horizonte/Minas Gerais, Brasil. E-mail: gariglioja@gmail.com

2 Doutor em Educação. Professor da Escola de Educação Física, Fisioterapia e Terapia Ocupacional da Universidade Federal de Minas Gerais (EEFFTO/UFMG). Belo Horizonte/Minas Gerais, Brasil.

E-mail: admir.almeidajunior@gmail.com

3 Doutor em Educação. Professor da Universidade Federal de Minas Gerais (UFMG). Belo Horizonte/Minas Gerais, Brasil. E-mail: clamoliv1974@hotmail.com 
THE "NEW" HIGH SCHOOL: implications to the process of legitimizing physical education

\begin{abstract}
The present work presents reflections about the mobilizing issue of this journal, namely: "how is it possible to find or construct foundations to justify Physical Education in the [high school] curriculum today?". In order to do so, we present a discussion about the main aspects of "New" High School, emphasizing the conceptions of knowledge, curriculum, youth and the rupture of the articulation between the dimensions of human formation (Science, Culture, Work and Technology) as they are treat in previous Legislation. Then, we return to the debate about the legitimacy of Physical Education in school, taking as reference, among other productions, the National Curricular Guidelines of Secondary Education published in 2006. Finally, we intend to present coping strategies of the current context, as well as reflect on the possibility of constructing other forms of legitimation of the presence and permanence of Physical Education in High School.
\end{abstract}

Keywords: High School. Physical Education. Curriculum. Educational Politicies. Pedagogical Legitimacy.

\title{
LA "NUEVA" ESCUELA SECUNDARIA: implicaciones para el proceso de legitimación de la educación física
}

\section{RESUMEN}

Este artículo presenta reflexiones sobre el tema de la conducción de esta revista, que es: “¿cómo se puede encontrar o construir las bases para justificar la educación física en los programas escolares [secundaria] hoy en día?". Por lo tanto, se presenta una discusión de los aspectos clave de la "nueva" de la escuela secundaria, haciendo hincapié en los conceptos de conocimientos, planes de estudio, los jóvenes y la ruptura de la relación entre las dimensiones del desarrollo humano (Ciencia, Cultura, Trabajo y Tecnología), siempre la legislación anterior. Luego reanudó el debate sobre la legitimidad de la educación física en la escuela, con referencia a, entre otras producciones, la plan nacional de estudios Directrices de Educación Secundaria escritas en 2006. Por último, tenemos la intención de presentar las estrategias de afrontamiento el contexto actual, así como reflexionar sobre la posibilidad de construir otras formas de legitimar la presencia y permanencia de la educación física en la escuela secundaria.

Palabras clave: Escuela. Educación Física. Plan de Estudios. Política Educativa. Legitimidade Pedagógica 


\section{INTRODUÇÃO ${ }^{4}$}

No segundo semestre de 2016, no contexto do golpe civil que tomou de assalto à sociedade brasileira, o "novo" Governo Federal encaminhou ao Congresso Nacional, de forma arbitrária, a medida provisória (MP) no 746/2016 que ficou conhecida como "MP da Reforma do Ensino Médio".

De maneira quase instantânea vimos ocorrer em nível nacional um movimento de contestação à proposta que se desdobrou em vários posicionamentos públicos de entidades científicas, tais como: Associação Nacional de Pós-Graduação e Pesquisa em Educação (ANPED), Sociedade Brasileira para o Progresso da Ciência (SBPC), Colégio Brasileiro de Ciências do Esporte (CBCE), dentre outras. Além disso, estudantes secundaristas e universitários protagonizaram um importante movimento de mobilização que utilizou como umas das principais estratégias as ocupações de escolas públicas de Ensino Médio e unidades acadêmicas de universidades.

As notas públicas emitidas pelas diferentes entidades científicas, assim como o movimento de ocupação dos estudantes, destacam a maneira arbitrária e autoritária da proposta que busca implantar uma reforma curricular por meio de medida provisória, desconsiderando o necessário diálogo com a sociedade civil, sobretudo os atores do contexto escolar: estudantes, docentes, gestores e comunidade. No tocante ao conteúdo, a MP também sofreu muitas críticas endereçadas, sobretudo, ao modo como a mesma aponta para a retomada de um modelo dualista de formação, com um tratamento distinto a alunos/as das redes públicas e privadas de ensino, contrapondo-se ao que preconiza a Lei de Diretrizes e Bases da Educação Nacional (Lei 9394/1996) que define o Ensino Médio como etapa final da Educação Básica, além de todo um conjunto de contribuições advindas de um intenso debate educacional realizado nos últimos anos.

No tocante ao campo da Educação Física, também fomos surpreendidos com a possibilidade de supressão desse componente curricular no Ensino Médio que se materializaria na não obrigatoriedade do mesmo em parte do trajeto formativo dos estudantes, fato que mobilizou um debate significativo em diferentes instâncias e contextos.

Nesse sentido, apresentamos neste texto um conjunto de reflexões que buscam apontar respostas possíveis ao convite/provocação apresentada pela editoria da Revista Motrivivência; para tanto, inicialmente, apresentamos uma discussão sobre os principais aspectos do "Novo" Ensino Médio, dando ênfase às dimensões que consideramos relevantes, tais como: concepções de conhecimento, currículo, juventudes e dimensões de formação humana (Ciência, Cultura, Trabalho e Tecnologia). Em seguida, apresentamos uma discussão mais centrada na questão mobilizadora desta sessão temática, qual seja: "como é possível encontrar ou construir fundamentos para justificar a Educação Física no currículo escolar [do ensino médio] hoje?, retomando um diálogo com Bracht (2001), além de tomarmos como referência algumas produções - sobretudo as Orientações Curriculares do Ensino

4 O presente trabalho não contou com apoio financeiro de nenhuma natureza. Não há quaisquer conflitos de interesses na realização deste trabalho. 
Médio - no intuito de apresentarmos estratégias de enfrentamento do atual contexto, bem como refletirmos sobre a possibilidade de construirmos outras formas de legitimação da presença e permanência da Educação Física no Ensino Médio.

\section{"CONTRARREFORMA" DO ENSINO MÉDIO: PRECARIZAÇÃO DO DIREITO À EDU- CAÇÃO, REFORÇO DA HIERARQUIZAÇÃO DOS SABERES ESCOLARES E O DÉFICIT DE LEGITIMIDADE PEDAGÓGICA DA EDUCAÇÃO FÍSICA}

A comunidade educacional no Brasil, no último ano, teve que reagir e lidar com uma contrarreforma do Ensino Médio, urdida por estratégias autoritárias impostas pelo governo Michel Temer. Foi quase unânime entre os pesquisadores das áreas, estudantes, professores e gestores escolares que uma reforma de tal vulto não poderia jamais ter sido feita por medida provisória, desrespeitando e solapando a vida e o cotidiano de quem está no epicentro da produção das práticas escolares nesta etapa da educação básica: a comunidade escolar, composta de alunos, professores, pais e funcionários.

$\mathrm{O}$ argumento principal utilizado pelo Governo Federal para justificar tal reforma se sustenta na tese do fracasso e/ou na crise do Ensino Médio. Para isso, o Ministério da Educação (MEC) faz uso indiscriminado ${ }^{5}$ de dados do Índice de Desenvolvimento da Educação Básica (IDEB), divulgados em 2016, que trata dos resultados negativos das escolas estaduais - resultados esses persistentes desde 2011 - como indicador da "falência do Ensino Médio". O governo, ao lançar mão desses dados, interpretou, como e com quem quis, os sinais da "crise do Ensino Médio", assumindo para si a forma e o conteúdo da mudança como se um único caminho fosse o possível (CARRANO, 2017).

Ao contrário do que tentam afirmar os gestores de plantão do MEC, os dados do IDEB deveriam ser tomados como referências e evidências da necessidade de um amplo debate nacional sobre os rumos do Ensino Médio, bem como sobre o teor de possíveis reformas que pudessem contribuir efetivamente com a melhoria da qualidade social da educação nesta etapa de escolarização. Ao contrário, o ritmo e o teor de tal reforma colocam em segundo plano questões basilares à garantia de uma educação de qualidade social: as condições objetivas e infraestruturais das escolas, a profissionalização e valorização dos profissionais da educação, a relação discente-turma-docente, a consideração dos jovens como sujeitos socioculturais, a inovação nas/das práticas pedagógicas, entre outros aspectos.

Um conjunto variado de estudiosos no campo educacional no Brasil vem problematizando os possíveis impactos (nefastos) dessa contrarreforma do Ensino Médio.

5 Para Freitas (2016), o argumento da crise do Ensino Médio alardeado pelo Governo Federal é, no mínimo, discutível. Segundo o autor, diferentemente da interpretação monocrática do MEC, os mesmos dados do IDEB mostram que em nenhum momento a média da avaliação das escolas públicas do Ensino Médio cai. Mesmo no "caos" do Ensino Médio, o IDEB das escolas públicas, avançou de 3,4 para 3,5. Pode ser argumentado que enquanto as escolas públicas têm média de 3,5, as privadas estão com 5,2. Todavia, elas têm metas diferentes: a meta da escola privada é 6,3 e a meta da escola pública (estadual) é 4. Enquanto a escola privada está a 1 ponto de sua meta, a escola pública está a 0,5 ponto da dela. Em certa medida, a escola pública estaria fazendo sua lição de casa melhor do que as privadas (isso no período entre os anos de 2004 a 2015). 
O primeiro ponto colocado em relevo é que há um vício de origem na proposta do MEC que é a retomada de uma concepção dualista que já havíamos superado na última LDB (Lei n. 9394/96) e que definiu o Ensino Médio como a etapa final da Educação Básica para todos. A concepção de Ensino Médio como parte orgânica da Educação Básica preconizada pela LDB afirma o caráter de formação geral comum, prevendo o aprofundamento para todos os estudantes dos conhecimentos científicos, éticos e estéticos adquiridos ao longo da Educação Básica6.

O retorno do "ufanismo" da profissionalização no Ensino Médio, preconizado na Lei 5692/71 e sua relação com a inserção imediata no mercado de trabalho está expresso, de forma velada, na instituição dos denominados "itinerários formativos"7 apontados no interior da MP. A ideia de organização dos currículos por itinerários formativos específicos, com ênfases em cinco áreas distintas e sem a área de Ciências Sociais, tende a conferir ao currículo um caráter utilitarista, voltado unicamente ao atendimento de perspectivas futuras de inserção no mercado de trabalho, negligenciando, também, a função de "formação para a cidadania" prevista na atual LDB. Esse reducionismo compromete a possibilidade de novas descobertas e ressignificações, tão comuns a essa fase da vida, reforçando a tendência de antecipação das decisões profissionais e de especialização do Ensino Médio. Essa perspectiva está presente no discurso do "Novo Ensino Médio" (Brasil, MEC, 2016), quando é afirmado que "as crianças e os jovens do Brasil têm pressa. A educação precisa avançar". O "avanço" é representado pela ideia de "flexibilização do currículo" pautada pela sua simplificação, redução e pragmatismo. ${ }^{8}$ Temos aqui um quadro em que a "flexibilização curricular" constitui uma falácia pelo fato dos itinerários formativos serem definidos pela oferta dos sistemas de ensino, oferta esta condicionada às suas condições econômicas, logísticas e de pessoal, que subtrai a real possibilidade de escolha pelos jovens matriculados no Ensino Médio.

O caráter restritivo da contrarreforma é evidente porque, como parte da Educação Básica, o Ensino Médio deveria abranger os três anos dessa etapa de escolarização. Quando falamos de Educação Básica, falamos de educação comum para todos. Assim, qualquer

6 A LDBN (1996) estabelece que o Ensino Médio é a etapa que completa a Educação Básica, definindo-a como a conclusão de um período de escolarização de caráter geral. O artigo 35 prevê que o Ensino Médio, etapa final da Educação Básica, com duração mínima de três anos, terá como finalidade: I - a consolidação e o aprofundamento dos conhecimentos adquiridos no Ensino Fundamental, possibilitando o prosseguimento de estudos; II - a preparação básica para o trabalho e a cidadania do educando, para continuar aprendendo, de modo a ser capaz de se adaptar com flexibilidade a novas condições de ocupação ou aperfeiçoamento posteriores; III - o aprimoramento do educando como pessoa humana incluindo a formação ética e o desenvolvimento da autonomia intelectual e do pensamento crítico; IV - a compreensão dos fundamentos científico-tecnológicos dos processos produtivos, relacionando a teoria com a prática, no ensino de cada disciplina.

7 Art. 36. O currículo do Ensino Médio será composto pela Base Nacional Comum Curricular e por itinerários formativos, que deverão ser organizados por meio da oferta de diferentes arranjos curriculares, conforme a relevância para o contexto local e a possibilidade dos sistemas de ensino, a saber: I - linguagens e suas tecnologias; II - matemática e suas tecnologias; III - ciências da natureza e suas tecnologias; IV - ciências humanas e sociais aplicadas; V - formação técnica e profissional (Redação dada pela Lei n 13.415, de 2017).

8 Sobre essa análise ver nota publicada pela A ABdC/Associação Brasileira de Currículo e o GT 12 Currículo da ANPEd/ Associação Nacional de Pós-graduação e Pesquisa em Educação. 
reforma do Ensino Médio deveria, entre outras coisas, preconizar o horizonte de universalização desta etapa, incorporando aqueles que estão fora das escolas e oferecendo condições físicas, materiais e de trabalho de forma a garantir uma educação com qualidade social.

Ao reduzir para o máximo de 1800 h a parte comum, das 3000 h previstas ${ }^{9}$ para conclusão do Ensino Médio, o MEC impõe um empobrecimento na formação dos nossos jovens $(40 \%$ do percurso formativo seria destinado/preenchido pelos "itinerários específicos"). Aqui o específico, por definição, se opõe ao que é comum: atacando na raiz a concepção de Ensino Médio como uma etapa com funções singulares e ao mesmo tempo orgânica à Educação Básica.

Essa concepção reducionista impressa na contrarreforma do Ensino Médio, portanto, acaba por interromper ou dificultar a formação de uma cidadania ampliada para todos (ética, técnico-científica, cultural-artística, de ampliação da consciência sobre o próprio corpo e de reconhecimento do direito de existir do outro). Dessa forma, ela se configura como um brutal retrocesso porque atua de forma a institucionalizar a desigualdade estrutural presente na sociedade brasileira concebendo uma escola de Ensino Médio aligeirada para os jovens "vocacionados" para o mercado de trabalho; enquanto mantém abertas as perspectivas de formação ampliada para os "predestinados" - em geral, herdeiros por origens de classe - ao Ensino Superior. Pode-se mesmo dizer que o MEC resolveu reorganizar o Ensino Médio brasileiro, notadamente o público, de forma reduzir a pressão de ingresso de jovens no Ensino Superior. Interrompe-se, assim, a tendência de universalização da mobilidade escolar que vinha se configurando, ainda que lentamente, na última década com as políticas públicas de cotas e financiamento do ingresso e permanência na universidade (CARRANO, 2017). Os alunos jovens das camadas populares ficam subtraídos do acesso a percursos formativos que não sejam pautados pela lógica utilitária e instrumental.

A contrarreforma do Ensino Médio imposta pelo governo não pode ser considerada fora do contexto de fragilidade institucional da democracia no Brasil ${ }^{10}$, da retomada do avanço neoliberal contra os direitos sociais e da abertura de oportunidades de negócios no campo educacional público para o grande capital nacional e internacional (CARRANO, 2017). O pano de fundo da reforma, portanto, é fortemente marcado pela lógica pragmática, utilitária e pelo ideário eficientista no campo educacional.

9 A carga horária do Ensino Médio subirá de 800 para 1,4 mil horas. As escolas farão a ampliação de forma gradual, mas nos primeiros cinco anos já devem oferecer 1.000 horas de aula anuais. A Base Nacional Curricular Comum (BNCC), que é obrigatória a todas as escolas, deverá ocupar o máximo de $60 \%$ da carga horária total do Ensino Médio, sendo o tempo restante preenchido por disciplinas de interesse do aluno, que poderá eleger prioridades de acordo com a área de formação desejada em uma das cinco áreas de interesse: linguagens, matemática, ciências da natureza, ciências humanas e formação técnica e profissional. Maiores detalhes no site http://www.brasil.gov.br/educacao/2017/02/conheca-as-mudancas-que-ocorrerao-no-ensino-medio.

10 Fragilidade democrática esta que, no campo educacional, já se manifesta em formulações, tanto em esfera municipal quanto estadual, de legislações denominadas de "Escola sem Partido", que em verdade trata-se de uma falácia que busca o silenciamento da experiência republicana de formação crítica nas escolas, bem como à redução do ato educativo a uma prescrição instrumental. Desejo incessante dos grandes conglomerados nacionais e internacionais de empresas prestadoras de serviço e materiais didáticos no campo de ensino. 
Neste contexto, o enxugamento do currículo no Ensino Médio não está desconectado da restrição orçamentária imposta pela PEC 55/2016 que limita por 20 anos os gastos públicos. Em conexão com essa legislação, o governo ao invés de tentar resolver o problema crônico da carência de professores no Ensino Médio, impõe o paliativo dos itinerários formativos, a possibilidade da contratação de professores com "notório saber", a validação e equivalência de atividades à distância e uma profissionalização sem vínculo orgânico com o projeto educacional das escolas do Ensino Médio. Neste horizonte, abre-se caminho ao avanço da privatização do Ensino Médio na medida em que as instituições privadas poderão abocanhar uma parcela da formação que deveria ser pública; e o interesse do "mercado de trabalho" que garantirá uma mão de obra cada vez mais barata pela redução de seus "custos de produção"11.

Temos aqui um importante recuo ante as orientações previstas nas Diretrizes Curriculares do Ensino Médio promulgadas no ano de 2012. Nestas diretrizes manifesta-se uma concepção de educação integral que prevê a garantia, aos jovens, do acesso e do aprofundamento de um conjunto mais ampliado de conhecimentos (científicos, culturais, éticos, estéticos, tecnológicos), necessários à compreensão do mundo em toda a sua complexidade, de forma que possam realizar escolhas conscientes para o "bem viver" de suas próprias vidas, o aprimoramento de si, a incorporação dos valores democráticos, enfim, para a participação e o aprimoramento da democracia (BRASIL, 2011). ${ }^{12}$

A perspectiva educacional expressa na contrarreforma do Ensino Médio revela-se diametralmente oposta a ideia de uma educação integral cujo caráter não é pautado pela lógica instrumental de formação. Assim, não foi surpresa que a presença Educação Física ${ }^{13}$ no currículo do Ensino Médio fosse questionada e sua permanência, como componente curricular obrigatório, colocada em xeque. ${ }^{14}$ Tal contrarreforma, portanto, acaba por

11 A MP em questão altera a regulamentação do Fundo de Desenvolvimento da Educação Básica (FUNDEB), cujos recursos poderão ser utilizados para financiar oferta de serviços educacionais por agentes não públicos. Também permite que parte do tempo de integralização do Ensino Médio ocorra, entre outras possibilidades, na forma de trabalho supervisionado em sistema produtivo. Considerando-se o enorme contingente de professores contratados por designação temporária nos sistemas de ensino, abre-se neste contexto a total desvalorização dos cursos de licenciatura no Brasil, através de um verdadeiro processo de "terceirização"da escola pública brasileira.

12 Saviani (2000) define muito bem a perspectiva de educação integral contida nas DCN do Ensino Médio de 2012. Para o autor, a educação integral do homem, a qual deve cobrir todo o período da Educação Básica que vai do nascimento, com as creches, passa pela Educação Infantil, o Ensino Fundamental e se completa com a conclusão do Ensino Médio por volta dos dezessete anos, é uma educação de caráter desinteressado (ou seja, não pautado pela lógica utilitarista e instrumental) que, além do conhecimento da natureza e da cultura, envolve as formas estéticas, a apreciação das coisas e das pessoas pelo que elas são em si mesmas, sem outro objetivo senão o de relacionar-se com elas.

13 A lógica utilitarista e instrumental contida na contrarreforma do Ensino Médio do governo Temer também colocou em xeque a existência/permanência no currículo de disciplinas também vistas como inúteis ao ideário neoliberal: Artes, Sociologia, Filosofia. Ao contrário de serem reconhecidas como campos fundamentais para o desenvolvimento integral da pessoa e o desenvolvimento da cidadania, são vistas como coisas que atrapalham a formação dos jovens, por não ratificarem um ethos instrumental de relação com o mundo do trabalho.

14 A Educação Física, no primeiro texto da contrarreforma do Ensino Médio apresentado pelo MEC, perdia o status de componente curricular obrigatório, ficando essa condição restrita à Educação Infantil e ao Ensino Fundamental. Não se sabe o porque, sobre quais argumentos e pressão de que grupos, no texto final ela retorna na condição de disciplina obrigatória. Esse fato é revelador do déficit crônico da legitimidade pedagógica da Educação Física e de seu desenraizamento curricular, em especial nesta etapa da Educação Básica. 
reforçar a fragmentação e hierarquia do conhecimento escolar que as Diretrizes Curriculares Nacionais do Ensino Médio, amplamente debatidas, buscaram enfrentar.

Nesta primeira parte do texto buscamos analisar mais detidamente as relações e princípios de poder instalados na nova organização curricular do Ensino Médio, que colocam em risco a perspectiva de educação integral contida nas Diretrizes Curriculares Nacionais do Ensino Médio (DCNEM). Na próxima parte do texto nos debruçaremos sobre as relações existentes entre o caráter reducionista e pragmático da contrarreforma do Ensino Médio e o risco de exclusão da Educação Física como componente curricular obrigatório neste ciclo de escolarização. Que interesses de classe, profissionais e institucionais não manifestos estão envolvidos no processo estratificação radical do conhecimento escolar imposto pela MP 746, que torna certas disciplinas escolares como excesso ou não mais necessárias ao projeto educacional em curso? Melhor dizendo, porque se atribui menor prestígio à Educação Física, comparativamente às disciplinas de Língua Portuguesa, Inglesa e Matemática?

\section{DESAFIOS À PRESENÇA E PERMANÊNCIA DA EDUCAÇÃO FÍSICA NO “NOVO" EN- SINO MÉDIO}

Levando-se em consideração o contexto da contrarreforma do Ensino Médio preconizado pela MP 746, abordaremos os riscos de um "não-lugar" da Educação Física no "Novo" Ensino Médio. Para tanto, vamos considerar o caráter tanto histórico quanto conjuntural da legitimidade da Educação Física na escola, bem como a ideia de currículo como um "território em disputa" (ARROYO, 2011) para se pensar as condições e formas de inserção e permanência deste componente curricular.

A primeira versão da MP 746 encaminhada ao Congresso Nacional apontava apenas os componentes curriculares de Matemática, Português e Inglês como obrigatórios, indicando que as demais disciplinas e seus respectivos conteúdos seriam definidos pela Base Nacional Curricular Comum (BNCC). Entre as várias questões polêmicas já discutidas no tópico anterior, na primeira versão da MP, os componentes curriculares de Arte, Educação Física, Filosofia e Sociologia deixariam de ser obrigatórios.

Após um intenso processo de debates e críticas, o texto aprovado voltou a incluir Educação Física e Arte como componentes curriculares obrigatórios, sem fazer menção ao futuro da BNCC. No caso específico da Educação Física, no último ano do Ensino Médio, a disciplina será optativa. Consideramos que o processo de exclusão iminente e, posteriormente, a frágil reinserção da Educação Física em parte dessa etapa formativa da Educação Básica nos mobiliza para a retomada da discussão acerca da legitimidade desse componente curricular no Ensino Médio.

Para estabelecer relações com as especificidades do campo da Educação Física vamos nos valer das contribuições teóricas trazidas pelo professor Valter Bracht. Em texto publicado no ano de 2001, esse autor inicia um instigante debate sobre a legitimidade da Educação Física Escolar na contemporaneidade. Valendo-se de fatos ocorridos no debate 
ocorrido no Congresso Nacional, quando da construção da atual LDB, o autor lembra que a Educação Física correu o risco de ser suprimida dos currículos escolares e que, em função de certa reação a mesma acabou sendo definida na LDB como componente curricular obrigatório. Para o autor, ficaram dúvidas, no entanto, se o texto legal refletiu um consenso mínimo e um reconhecimento público de sua importância educacional.

Tomado esse acontecimento como ponto de partida, Bracht (2001) buscar encontrar respostas mais consistentes do porque os pensadores e formuladores do projeto de educação liberal-burguês (presentes e atuantes no debate sobre os rumos da LDB na década de 1990) acabaram por se desinteressar pela Educação Física enquanto componente curricular. Por que a pedagogia conservadora desinteressou-se pela Educação Física? Quais funções ela cumpria e que agora estão fora dos interesses da pedagogia conservadora?

No intuito de historicizar a discussão sobre a entrada e permanência da Educação Física nos currículos escolares, Bracht lembra que sua inserção como componente curricular remonta aos próprios primórdios da escola moderna. Sua inserção no currículo escolar se deveu à conjunção de uma série de fatores, todos eles condicionados pela emergência de uma nova ordem social nos séculos XVIII e XIX. Movimentos no plano da medicina que por sua vez estariam ligados ao surgimento e desenvolvimento do Estado Nacional, como também da própria educação, são determinantes. Assim, as afirmações ou conclusões da medicina são interpretadas pedagogicamente e traduzidas em estratégias de ação que envolvem também a escola e a educação do povo para a saúde. O Estado Nacional burguês pretendia ampliar tal educação para a população como um todo, na qual a Educação Física (ainda sem essa denominação, mas com a ideia de uma educação corporal fortemente marcada por princípios médico-higienistas) era uma estratégia fundamental.

No desenvolvimento de sua argumentação, o autor lembra que a sustentação desse modelo está na dependência da permanência ou não das condições objetivas que lhe deram origem. Bracht (2001) vai apontar quatro condições básicas, a saber: a importância da aptidão física para a produtividade no trabalho, quer dizer a Educação Física era vista também como uma forma de garantir a produtividade do trabalhador, da população como um todo, para a produtividade do Estado Nacional; a relação do Estado para com as questões da saúde, na qual o Estado seria grande responsável, em especial a partir de seu modelo de Estado do Bem-Estar social; a predominância da visão médica do corpo, quer dizer o corpo como máquina, assim como tratado pela medicina; a ideia do trabalho como dever, na qual a ética do trabalho apresenta-se como uma ética fundamental para o desenvolvimento do capitalismo. Condições estas que vão sustentar a Educação Física na escola.

Para Bracht (2001), essas bases de sustentação do modelo que legitimava a Educação Física na escola estariam sendo corroídas por estarmos diante de mudanças sociais significativas. É sobre essas mudanças e seus possíveis impactos sobre o processo de legitimação da Educação Física Escolar que o autor continua a desenvolver sua argumentação. Para ele, a corrosão das bases legitimadoras da Educação Física escolar podem ser analisadas sob cinco aspectos: 
1. A aptidão física é cada vez menos importante como determinante para a produtividade no trabalho (estamos na era do trabalho intelectual e da produção imaterial), no sentido do uso da força/capacidade física de produzir.

2. Embora a saúde e a educação ainda constem da agenda estatal, é claro e notório o deslocamento para a iniciativa privada dessa responsabilidade, iniciativa privada tanto pessoal, quanto empresarial. As pessoas hoje são levadas a buscar a prestação de serviços da iniciativa da privada para o movimentar-se, para a atividade física, academias, o que revelaria a retirada do Estado dessa função.

3. A reformulação do próprio conceito de saúde, retirando-lhe o caráter exclusivamente ou eminentemente biológico. Tal deslocamento, por sua vez, faria que a contribuição da Educação Física se relativizasse, perdendo centralidade.

4. A mudança na questão do trabalho, cujas ideias de trabalho como dever e do prazer como recompensa convivem hoje com a valorização do lazer, de forma que a cultura criada, vivenciada, fruída no "tempo livre" passa a ser tão importante para a realização do homem quanto o trabalho. Uma vez que a referência do modelo que sustentava a Educação Física foi o trabalho, a mesma estaria - direta ou indiretamente - em xeque nos dias de hoje.

5. As mudanças de legitimação do fenômeno esportivo que hoje prescinde dos discursos da educação e da saúde para se legitimar via sua importância econômica. (cf, BRACHT, 2001).

Segundo Bracht (2001) tais mudanças sociais e econômicas podem ajudar a explicar porque o projeto liberal burguês de educação estaria prescindindo da Educação Física Escolar. Dialogando com a atual conjuntura, fica evidente que a exclusão/retorno precarizado ${ }^{15}$ da Educação Física como componente curricular obrigatório que se deu no debate sobre a versão final da MP 746 tem relação direta com o tipo de modelo educacional veiculado pelo discurso oficial do governo Michel Temer. Como vimos, a contrarreforma do Ensino Médio busca impor o profissionalismo estreito e precoce, a retirada de conhecimentos fundamentais à formação estética, ética e crítica dos estudantes, em troca de uma falsa flexibilidade curricular. Quando a lógica do neotecnicismo do projeto de liberal burguês se afirma de forma tão radical nas políticas educacionais, tal como vimos na contrarreforma do Ensino Médio, se instaura a ideia de que de que determinados componentes curriculares podem simplesmente desaparecer do currículo escolar.

Sobre esse ponto é importante ressaltar que na contrarreforma do Ensino Médio as disciplinas escolares tornam-se o alvo a ser combatido, não só pela quantidade delas no currículo vigente, como pelo modo como supostamente estariam funcionando no Ensino Médio. As disciplinas são lidas como descontextualizadas, como capazes de apoiar uma visão fragmentada de mundo, consolidando uma formação superficial e extensa dos jovens, além de impossibilitar uma diversificação dos sistemas de ensino devido à ocupação de vasto espaço da carga horária na grade escolar. Ao final, parece prevalecer apenas a ideia

15 Os motivos que levaram os legisladores, quando da definição final da versão do texto final da MP 746, que tratava das modificações concernentes ao Ensino Médio, a retirar e reinserir a Educação Física como componente curricular obrigatório (em poucos meses), são obscuros ou imprecisos. Não se tem clareza dos argumentos de caráter epistemológico, social, cultural ou mesmo políticos e corporativos, que sustentaram a permanência da Educação Física no currículo do Ensino Médio na versão final do texto em questão. 
de que a maior variedade disciplinas é um problema para o financiamento da educação. É totalmente desconsiderado que, por maiores que sejam as possíveis críticas à organização disciplinar, as disciplinas têm história, vínculos com carreiras docentes e expectativas sociais e não devem ser tratadas de forma naturalizada ou como repositórios de saberes. A proposta inicial de retirar do currículo disciplinas como Artes, Educação Física, Filosofia e Sociologia é apenas uma das evidências de que as disciplinas não são tratadas como instituições sociais que têm vínculos como variados projetos em curso nas escolas (OLIVEIRA; SUSSEKIND, 2017).

Todavia, neste debate faz-se necessário ressaltar que nem todas as disciplinas são vistas como problemas, descontextualizadas, anacrônicas ou empecilhos ao processo de implementação de um denominado projeto educacional, assim como sua presença não é tolhida frente aos limites orçamentários. Com a contrarreforma do Ensino Médio temos a expressão de uma radicalização das hierarquias dos saberes escolares e a manifestação clara de que determinados conhecimentos valem muito mais do que outros. Isso porque no bojo desta contrarreforma determinadas disciplinas (Matemática, Língua Portuguesa e Inglesa) que já gozavam de alto status curricular ganharam ainda mais importância e reconhecimento pedagógico.

A Educação Física, por tratar pedagogicamente, na escola, de saberes vinculados mais fortemente ao universo da experiência comum e do cotidiano (jogos, danças, esportes, ginástica) do que de conhecimentos advindos de disciplinas acadêmico-científicas, ou, então, de forma mais geral, de saberes de caráter teórico-conceitual (abstratos); pela relação estreita dos seus saberes com o espaço/tempo do mundo do lazer (prática social essa com menos status comparativamente com o mundo do trabalho); e por ser uma ação pedagógica impregnada de experiências estéticas (corporais, grupais, relacionais, comunicativas, vivências essas de difícil codificação e avaliação da aprendizagem individual dos alunos) acaba por enfrentar grandes dificuldades de legitimação e reconhecimento no currículo escolar, sobretudo em um cenário educacional no qual a "boa educação" significa ter boas notas em Português, Matemática e Inglês.

Portanto, neste cenário de radicalização da lógica eficientista no campo educacional, sobretudo no Ensino Médio, a legitimidade pedagógica da Educação Física estará fortemente fragilizada. A sua sobrevida no currículo escolar ficou evidente no processo de elaboração da versão final do texto da MP 746. Ela ainda respira por aparelhos, frágil, dependente de políticas educacionais de ocasião. Seria possível pensar a inserção da Educação Física no Ensino Médio dentro de um projeto educacional emancipatório? Que saídas e alternativas são possíveis para a Educação Física neste atual quadro político/institucional?

\section{ANUNCIANDO PERSPECTIVAS: LEGITIMIDADES E ENFRENTAMENTOS DA EDUCA- ÇÃO FÍSICA ESCOLAR FACE AO ENSINO MÉDIO NEOLIBERAL}

Os acontecimentos ocorridos no bojo da contrarreforma do Ensino Médio desafiam os pertencentes ao campo da Educação Física (pesquisadores, professores, movimento 
estudantil) à produção de argumentos mais consistentes acerca da legitimidade da sua presença/permanência como componente curricular. Esse desafio apresenta-se mais complexo uma vez que se torna necessária a produção de argumentos dentro de marcos políticos e ideológicos diferentes aos propagados pela pedagogia liberal burguesa, ainda mais na sua faceta contemporânea neoliberal. Neste sentido, a teorização crítica no campo da Educação Física é desafiada a produzir novos sentidos às suas práticas escolares no Ensino Médio, em franco diálogo com as juventudes e seus projetos de vida, com mundo do trabalho (e não com o mercado), com o mundo do lazer e com a necessidade de produção de uma educação com qualidade social.

Esse é o desafio a que nos propomos neste momento. Para tanto, lançaremos mão de um exercício de revisitar algumas produções e dispositivos legais, dentre as quais as Diretrizes Curriculares Nacionais para o Ensino Médio (DCNEM) e as Orientações Curriculares do Ensino Médio escritas em 2006, as quais a contrarreforma desconsidera de forma explícita.

No parecer elaborado para a homologação das DCNEM encontramos uma compreensão de que o Ensino Médio, como etapa final da Educação Básica, deve estruturar-se de modo a garantir uma experiência formativa aos jovens estudantes pautada na noção da educação com qualidade social. Nesse sentido, em detrimento de uma noção de qualidade na educação que prevaleceu na década de 1990 - em que interessava o rendimento das escolas e dos estudantes em termos de eficácia e eficiência - o conceito de qualidade social da educação que emergiu do interior de movimentos sociais e de renovação pedagógica está intimamente associado à noção de direito à educação comprometida com a superação de desigualdades e injustiças sociais. (BRASIL, 2013, p.151)

Em direção oposta à contrarreforma, as DCNEM destacam a necessidade das escolas de Ensino Médio se reinventarem em face da noção de qualidade social da educação, para tanto, apresentam quatro pressupostos e/ou fundamentos para uma experiência de escolarização no Ensino Médio, quais sejam: trabalho, ciência, tecnologia e cultura.

Trabalho, ciência, tecnologia e cultura são considerados como princípios educativos e constituem-se nas bases da proposta de formação e de desenvolvimento curricular no Ensino Médio, ressaltando-se a compreensão de que essas dimensões/campos são interdependentes e possuem a marca de sua condição de produção humana, portanto histórico-cultural.

Para efeito deste texto, buscaremos dialogar de forma mais intensa com as noções de trabalho e cultura, buscando relacioná-las ao desafio de construção de outras possibilidades de legitimação da Educação Física nos currículos do Ensino Médio.

O trabalho é considerado como um princípio educativo na sua dimensão ontológica e histórica, ressaltando o mesmo como uma produção humana e fruto da ação intencional para criar e transformar a realidade. Ao mesmo tempo, o trabalho também é compreendido como prática econômica, visto que o mesmo ainda é a principal ação humana que garante a existência, por meio da produção de riquezas e satisfação de necessidades.

Parece-nos potente buscarmos construir relações do componente curricular Educação Física com a compreensão do trabalho como um princípio educativo. Nesse sentido, 
ainda que concordemos com as afirmações de Bracht (2001) no tocante às profundas transformações ocorridas no mundo do trabalho e, consequentemente, um progressivo esvaziamento do discurso legitimador da presença da Educação Física nos currículos escolares, parece-nos imprescindível que o campo da Educação Física elabore e/ou ressignifique sua relação com o mundo do trabalho. Uma possibilidade talvez seja superar uma relação dualista e hipostasiada entre trabalho e lazer. É importante considerarmos tanto o trabalho quanto o lazer como dimensões relevantes e constitutivas da produção de identidades e subjetividades, sobretudo os estudantes jovens, em especial aqueles inseridos no Ensino Médio noturno ou no Ensino Médio presente na modalidade de EJA (Educação de Jovens e Adultos). Sujeitos estes tornados "invisíveis" no texto da MP 746.

Neste sentido, dialogamos com Dayrell (2007) ao apontar o trabalho e a escolarização como projetos que se superpõem na vida dos jovens das camadas populares, de forma que a condição juvenil só é vivenciada porque trabalham, garantindo o mínimo de recursos para o lazer, o namoro ou o consumo. Para ao autor, o mundo do trabalho aparece como uma mediação efetiva e simbólica na experimentação da condição juvenil na realidade brasileira, bem distinta de uma situação de juventude pautada pela moratória em relação ao trabalho, como ainda é comum em alguns países europeus.

Isto implica, portanto, na necessária problematização do mundo do trabalho nas escolas de Ensino Médio, uma vez que o trabalho aparece como constitutivo da realidade e das identidades destes sujeitos. Este aspecto é abordado da seguinte forma pelo documento referente aos Conhecimentos de Educação Física, presente nas Orientações Curriculares do Ensino Médio de 2006:

Não queremos aqui desconsiderar que o trabalho faça parte ou até justifique, de certa maneira, a política de Ensino Médio na educação escolar moderna. Queremos sim, destacar que as questões sobre o esforço e o repouso corporal devem fazer parte de uma discussão acerca do mundo do trabalho. O que é bem diferente dos discursos que tratam de uma falsa relação funcional direta entre as práticas corporais vivenciadas na escola como forma de adaptação às atividades desempenhadas no processo produtivo do trabalho diário (BRASIL, 2006, p. 224).

Considerar o trabalho nessa perspectiva implica outro olhar para com os sujeitos do Ensino Médio, no caso, os sujeitos jovens como sujeitos socioculturais, o que demanda a ruptura de visões estereotipadas que colocam os jovens como um "vir a ser", uma "passagem para a vida adulta", marcados pela experiência da espontaneidade, do hedonismo e, nos casos dos jovens pobres e negros, pela vagabundagem e pela marginalidade. Segundo Dayrell (2007), faz-se necessário superar generalizações apressadas e dicotômicas sobre os jovens pobres, identificando-os de forma homogênea com a delinquência e a criminalidade ou, no seu oposto, com uma imagem "romântica", na qual inexistem conflitos, tensões e violências. Ao analisar o aumento das taxas de expansão de matrículas a partir da década de 1990, o autor aponta o seguinte paradoxo acerca dos processos de escolarização dos sujeitos jovens no Brasil: 


\begin{abstract}
Se a escola se abriu para receber um novo público, ela ainda não se redefiniu internamente, não se reestruturou a ponto de criar pontos de diálogo com os sujeitos e sua realidade. Além do mais, predomina uma representação negativa e preconceituosa em relação aos jovens, reflexo das representações correntes sobre a idade e os atores juvenis na sociedade. É muito comum, nas escolas, a visão da juventude tomada como um "vir a ser", projetada para o futuro, ou o jovem identificado com um hedonismo individualista ou mesmo com o consumismo. Quando se trata de jovens pobres, ainda mais se forem negros, há uma vinculação à ideia do risco e da violência, tornando-os uma "classe perigosa". Diante dessas representações e estigmas, o jovem tende a ser visto na perspectiva da falta, da incompletude, da irresponsabilidade, da desconfiança, o que torna ainda mais difícil para a escola perceber quem ele é de fato, o que pensa e é capaz de fazer. A escola tende a não reconhecer o "jovem" existente no "aluno", muito menos compreender a diversidade, seja étnica, de gênero ou de orientação sexual, entre outras expressões, com a qual a condição juvenil se apresenta (DAYRELL, 2007, p. 1117).
\end{abstract}

Nessa perspectiva, cabe pensar a Educação Física em diálogo com uma noção de juventudes ${ }^{16}$ que os reconheça como sujeitos de direitos na elaboração, criação e experimentação de suas práticas corporais. Mais uma vez o texto das Orientações Curriculares do Ensino Médio (2006) referente à Educação Física nos aponta reflexões e princípios emblemáticos a esse respeito:

O que se espera é que os alunos do ensino médio tenham a oportunidade de vivenciarem o maior número de práticas corporais possíveis. Ao realizarem a construção e a vivência coletiva dessas práticas, estabelecem relações individuais e sociais, tendo como pano de fundo o corpo em movimento. Assim, a ideia é a de que esses jovens adquiram maior autonomia na vivência, criação, elaboração e organização dessas práticas corporais, assim como uma postura crítica quando estes estiverem no papel de espectadores das mesmas. Espera-se, portanto, que os saberes da Educação Física tratados no ensino médio possam preparar os jovens para uma participação política mais efetiva no que se refere à organização dos espaços e recursos públicos de prática de esporte, ginástica, dança, luta, jogos populares, entre outros ${ }^{17}$ (BRASIL, 2006, p.224-225, grifos nossos).

Também nos parece muito importante ampliarmos nossa relação com a dimensão educativa da cultura, para isso, novamente vamos nos valer da compreensão de cultura

16 O plural aqui não é gratuito, pois entendemos juventudes a partir de seu caráter plural e relacional, cuja diversidade cultural e as diferentes formas de ser jovem dialogam com outros pertencimentos identitários como gênero, raça/etnia, orientação sexual, procedência regional/territorial e, não menos importante, sua classe social e seu acesso aos bens econômicos. (cf. DAYRELL, 2007).

17 No esteio destes princípios, o referido documento aponta as seguintes garantias aos alunos no currículo de Educação Física no Ensino Médio: acúmulo cultural no que tange à oportunização de vivências das práticas corporais; participação efetiva no mundo do trabalho no que se refere à compreensão do papel do corpo no mundo da produção, no que tange ao controle sobre o próprio esforço e do direito ao repouso e ao lazer; iniciativa pessoal nas articulações coletivas relativas às práticas corporais comunitárias; iniciativa pessoal para criar, planejar e buscar orientação para suas próprias práticas corporais; intervenção política sobre as iniciativas públicas de esporte, lazer e organização da comunidade nas manifestações, vivência e na produção da cultura (cf. BRASIL, 2016). 
expressa nas DCNEM. No texto cultura é entendida como o resultado de uma ação coletiva com objetivo de conservar a vida humana e, ao mesmo tempo, consolidar formas produtivas das sociedades. Desse processo resultam produções humanas singulares relacionadas aos campos das expressões materiais e simbólicas, bem como representações e significados que correspondem a valores éticos e estéticos de um determinado grupo social (BRASIL, 2013, p. 162).

Nessa direção, é importante lembrarmos que os temas e conteúdos a serem apresentados aos estudantes do Ensino Médio estão vinculados a um conjunto expressivo de práticas corporais produzidas no interior de diferentes contextos culturais. Sendo assim, tais práticas também são, elas próprias, culturais. É justamente essa característica que faz com que os sujeitos que experimentam e se apropriam delas elaborem diferentes sentidos e significados para as mesmas. Ao tomarem contato com essas práticas corporais, estudantes do Ensino Médio podem relacionar-se com tais conhecimentos tendo como referência tanto sua trajetória específica de escolarização como as marcas constitutivas de sua subjetividade. Com isso queremos afirmar a necessidade de que o contato com as aulas de Educação Física no Ensino Médio possibilite aos estudantes o processo de síntese de experiências, vivências e aprendizagens elaboradas no transcurso da Educação Básica, bem como a elaboração de novos sentidos e significados nessa etapa formativa. O que é bem diferente de uma visão meramente instrumental de relação com as práticas corporais. Ao situar a Educação Física no campo das linguagens, as Orientações Curriculares do Ensino Médio (2006) apontam claramente este outro sentido para este componente curricular nesta etapa final da Educação Básica:

\begin{abstract}
A leitura da realidade pelas práticas corporais permite fazer com que essas se tornem "chaves de leitura do mundo". As práticas corporais dos sujeitos passam a ser mais uma linguagem, nem melhor nem pior do que as outras na leitura do real, apenas diferentes e com métodos e técnicas particulares. Pode-se dialogar em uma aula de Educação Física com outras linguagens, como a escrita e a audiovisual. Porém, as práticas corporais possuem valores nelas mesmas, sem a necessidade de serem "traduzidas" para outras linguagens para obter o seu reconhecimento. Estão diretamente ligadas a uma formação estética, à sensibilidade dos alunos. Por meio do movimento expressado pelas práticas corporais, os jovens retratam os valores em que eles vivem: seus valores culturais, sentimentos, preconceitos, etc. Também "escrevem" nesse mesmo mundo suas marcas culturais, construindo os lugares de moças e rapazes na dinâmica cultural. Por vezes, acabam eles próprios se tornando "modelos culturais", nos quais uma certa "ideia de juventude" passa a ser experimentada, copiada e também vivida por outras gerações (BRASIL, 2006, p.218).
\end{abstract}

Compreensão acerca das práticas corporais que não é nova, mas que remonta ao movimento renovador da Educação Física das décadas de 1980 e 1990, articulado a uma perspectiva progressista de educação. Concepções em disputa no território epistemológico e curricular do campo pedagógico. 


\section{CONSIDERAÇÕES FINAIS}

Como assinalado anteriormente o contexto da contrarreforma do "novo" Ensino Médio colocou a Educação Física frente a um "velho" dilema: como (re)construir argumentos que apontem para a presença e permanência da Educação Física no Ensino Médio? Como enfrentar a possibilidade e o risco de um "não-lugar" para a Educação Física no Ensino Médio?

Ao longo do texto buscamos evidenciar que as respostas a esse dilema passam necessariamente por um processo de enfrentamento das bases que sustentam o "novo" Ensino Médio. No caso específico da Educação Física esse enfrentamento deve se dar por meio de uma retomada ou aproximação mais qualificada e radical com determinadas dimensões educativas que são fundamentais para um processo de formação dos estudantes, quais sejam: o trabalho, ciência, cultura e tecnologia. A questão da legitimidade pedagógica da Educação Física no Ensino Médio deve ser enfrentada com exercício crítico e criativo de reconstrução desse componente curricular, resgatando a compreensão do Ensino Médio como um ciclo constitutivo da Educação Básica. Neste sentido, a polissemia perversa de termos, tais como "flexibilidade curricular" (que se concretiza como uma "escola pobre para pobres") e "pluralidade" e "imparcialidade" (vinculadas à lógica de mercado e a doutrinas de pensamento único neoliberal) precisam ser criticadas à luz da denúncia de um contexto de repolitização conservadora da educação e da sociedade, no qual certos componentes curriculares, entre eles a Educação Física, são secundarizados em suas possibilidades de formação.

Parece-nos pertinente ressaltar a necessidade de ampliação de pesquisas e estudos no âmbito acadêmico que discutam a presença da Educação Física no Ensino Médio. Conforme destacam Rufino et al (2014) ainda são poucos os estudos que buscam discutir e apresentar elementos que contribuam para o esclarecimento das contribuições desse componente curricular para o processo de formação humana dos estudantes que frequentam as escolas de Ensino Médio no Brasil.

Entendemos que a afirmação da disciplina/componente curricular da Educação Física passa necessariamente pelo enfrentamento por outra escolarização e outra sociedade. Uma escolarização que preze, nos termos de Arroyo (2011), pelo não esquecimento de coletivos segregados e marginalizados, na escola e fora dela: os sujeitos da Educação de Jovens e Adultos, as comunidades indígenas e quilombolas, os moradores das periferias urbanas, os sujeitos em situação de privação de liberdade, os grupos LGBT, entre outros. Coletivos que contestam as normatizações curriculares, a lógica de mercado, as teorias pedagógicas e, por conseguinte, a própria Educação Física. Uma Educação Física que, como linguagem, poderia ser uma excelente "chave de leitura do mundo" a partir das relações de sociabilidade destes coletivos.

De posse disso, poderíamos pensar uma Educação Física no Ensino Médio que não negue o esclarecimento crítico, mas não o restrinja à razão. Uma Educação Física que faça dialogar a noção de corpo biológico com o corpo estético, em uma leitura ampliada de criticidade. Leitura esta que não seria propriedade do componente curricular da Educação 
Física, mas que não prescindiria da mesma para sua realização. Nas palavras de Valter Bracht (2001):

É preciso considerar a educação estética ou da sensibilidade como elemento importante do que poderíamos chamar de criticidade, quer dizer, a ideia de criticidade é uma ideia muito centrada na razão, ou de racionalidade como dimensão intelectual (às vezes restrita à ciência ou à racionalidade científica). Isso significa que a recuperação do corpo como sujeito pode fazer com que reformulemos o nosso conceito de criticidade, ampliemos o nosso conceito de razão, englobando as dimensões estéticas e éticas. A atual hegemonia do conhecimento científico na escola precisa ser flexibilizada para permitir que outros saberes se legitimem. Somente na medida em que se reconhecem como legítimos outros saberes que não os de caráter conceitual ou intelectual é que temos uma chance de nos afirmarmos [a Educação Física] no currículo escolar (BRACHT, 2001, p.77)

Desnecessário afirmar aqui que, em tempos sombrios nos quais nos encontramos, temos muito a lutar e a fazer. Um lutar e um fazer cotidianos para que uma inserção da Educação Física no Ensino Médio não se construa, mais uma vez, com uma legitimidade pautada pelo dualismo entre ensino propedêutico e ensino profissional, pelos ditames da lógica de mercado e por uma racionalidade puramente tecnicista e instrumental.

\section{REFERÊNCIAS}

ARROYO, M. Currículo, território em disputa. Petrópolis: Vozes, 2011.

BRACHT, V. Saber e fazer pedagógicos: acerca da legitimidade da educação física como componente curricular. In: CAPARROZ, F. E. (Org). Educação Física Escolar: Política, investigação e intervenção. Vitória: Proteoria, 2001, p. 67-80.

BRASIL. Ministério de Educação e Cultura. Lei $\mathbf{n}^{\mathbf{0}}$ 9394, de 20 de dezembro de 1996. Estabelece as diretrizes e bases da Educação Nacional. Brasília: MEC, 1996.

BRASIL. Ministério da Educação. Secretaria de Educação Básica. Orientações Curriculares para o Ensino Médio. Linguagens, Códigos e suas tecnologias, Volume 1, 2006.

BRASIL. Ministério da Educação. Diretrizes Curriculares Nacionais da Educação Básica. Secretaria de Educação Básica. Conselho Nacional da Educação. Câmara Nacional de Educação Básica. Brasília: MEC, SEB, DICEI, 2013.

BRASIL. Diário Oficial da União. Medida Provisória $\mathbf{n}^{0}$ 746/2016. Ano CLIII, n. - 184A Brasília - DF, sexta-feira, 23 de setembro de 2016. Disponível em: < http:// pesquisa.in.gov.br/imprensa/jsp/visualiza/index.jsp?jornal $=1000 \&$ pagina $=1 \&$ da ta $=23 / 09 / 2016>$. Acesso em: 30 Abr. 2017.

BRASIL. Ministério da Educação. Diretrizes Curriculares Nacionais da Educação Básica. Secretaria de Educação Básica. Conselho Nacional da Educação. Câmara Nacional de Educação Básica. Brasília: MEC, SEB, DICEI, 2013.

CARRANO, P. Um "novo" ensino médio é imposto aos jovens no Brasil. Disponível em: $<$ http://www.anped.org.br/news/um-novo-ensino-medio-e-imposto-aos-jovens-nobrasil >. Acesso em: 30 abr. 2017. 
DAYRELL, J. A escola faz juventudes? Reflexões sobre a socialização juvenil. Educação \& Sociedade. Campinas, v. 28, n.100, p.1105-1111, out.2007.

FREITAS, L. C. IDEB: 10 razões que contrariam a "tragédia" anunciada. Disponível em: < https://avaliacaoeducacional.com/2016/09/09/ideb-10-razoes-que-contrariam-atragedia-anunciada/ > . Acesso em: 30 Abr. 2017.

OLIVEIRA, I. B.; SUSSEKIND, M. L. Posicionamento sobre a Medida Provisória 746/2016 sobre o ensino médio. Disponível em: < https://blogdopensar.files.wordpress. com/2016/10/posicionamento-sobre-a-medida-provisc3b3ria-do-em_abdc-1.pdf. > . Acesso em: 30 abr. 2017.

RUFINO, L. G. B. et al. Educação Física Escolar no Ensino Médio: analisando o estado da arte. Revista Brasileira de Ciências do Esporte. Florianópolis, v. 36. n.2, supl., p. 353- 369, abr./jun. 2014.

SAVIANI, D. A educação musical no contexto da relação entre currículo e sociedade. Revista HISTEDBR on line, n 1, 2000. Disponível em: < http://www.histedbr.fae. unicamp.br/reder2.html>. Acesso em: 30 abr. 2017.

Recebido em: abril/2017 Aprovado em: julho/2017 